eCommons@AKU

January 2013

\title{
Intimate partner violence and mental health effects: A population-based study among married women in Karachi, Pakistan
}

Tazeen S. Ali

Aga Khan University, tazeen.ali@aku.edu

Ingrid Mogren

, Obstetrics and Gynecology, Umeå University, Sweden

Gunilla Krantz

The Sahlgrenska Academy at the University of Gothenburg, Göteborg, Sweden

Follow this and additional works at: https://ecommons.aku.edu/pakistan_fhs_son

Part of the Nursing Midwifery Commons

\section{Recommended Citation}

Ali, T. S., Mogren, I., Krantz, G. (2013). Intimate partner violence and mental health effects: A population-based study among married women in Karachi, Pakistan. International Journal of Behavioral Medicine, 20(1), 131-139.

Available at: https://ecommons.aku.edu/pakistan_fhs_son/169 


\section{Accepted in International Journal of Behavioral Medicine}

Intimate partner violence and mental health effects: a population-based study among married women in Karachi,

\section{Pakistan}

Tazeen S Ali ${ }^{1,2}$, Ingrid Mogren ${ }^{3}$, Gunilla Krantz ${ }^{4}$

${ }^{1}$ School of Nursing \& Department of Community Health Sciences, Aga Khan University, Karachi, Pakistan

${ }^{2}$ Department of Public Health Sciences, Division of Global Health (IHCAR), Karolinska Institutet, Stockholm, Sweden.

${ }^{3}$ Department of Clinical Science, Obstetrics and Gynecology, Umeå University, Sweden.

${ }^{4}$ Dept of Community Medicine and Public Health/Social Medicine, the Sahlgrenska Academy at the University of Gothenburg, Göteborg, Sweden.

\section{Correspondence:}

Tazeen Saeed Ali

RN, RM, BScN, MSc Epidemiology

Assistant Professor, School of Nursing \& department of Community Health Sciences, Aga Khan University, Karachi Pakistan

PhD student, Division of Global Health (IHCAR), Department of Public Health Sciences, Karolinska Institutet, Stockholm, Sweden

Stadium Road, PO Box 3500 
Karachi 74800

Pakistan

Tel: 00922134865460 and 00923232063073

E-mail: tazeen.ali@aku.edu 


\section{ABSTRACT}

Background: Intimate partner violence (IPV) is recognized all over the world for its association with mental ill-health in women. In Pakistan, such violence occurs commonly, but detailed information on mental health effects is scarce. This study focused on married couples in urban Karachi to investigate mental health effects associated with physical, sexual and psychological violence perpetrated by husbands towards wives. Disclosure rates, and health care seeking behaviour were also investigated.

Methods: This cross-sectional study involved 759 women between the ages of 25 to 60 years, selected using a multi-stage random sampling technique. The women were interviewed by trained community midwives using a structured questionnaire.

Results: In the total population of women, mental symptoms were prevalent. Women subjected to any form of violence however, reported considerably poorer mental health than unexposed women. A statistically significant difference for almost all of the studied health parameters persisted even after controlling for socio-demographic factors. The strongest associations were found for suicidal thoughts and physical violence (OR 4.11; 3.00-5.74), sexual abuse (OR 4.13 ;3.01-6.00); and psychological abuse (OR 5.05; 3.17-8.01).

The interviews revealed that only 27 percent of the women subjected to violence had disclosed this to anyone, in most cases to their parents.

Conclusion: The findings in this study point at IPV and other stressors women face that cumulatively contribute to the development of different forms of psychological stress and serious mental ill health. Women's life circumstances are surrounded by restrictions that seriously hamper women's empowerment and mental health. We highlight the need for a reliable health surveillance system and healthcare services that are able to serve abused women, in addition to 
policy initiatives that address violence within marriages which is a serious gender inequality in this society.

Key words: intimate partner violence, domestic violence, mental health effects, depression, suicidal thoughts, coping.

\section{Word Count}

Abstract: 284

Manuscript: 4440

Running heading: Mental health effects of IPV 


\section{INTRODUCTION}

Intimate partner violence (IPV) against women is recognized all over the world for its effects on women's mental health $(1,2)$. Public Health studies conducted in the United States, Brazil, Vietnam, and Ethiopia report strong associations between physical, sexual, and psychological IPV and mental symptoms, such as depression and anxiety; memory and concentration problems; and suicidal thoughts and completed suicides (3-7). The recently released findings from the WHO multi-country study on violence against women and its association with suicide attempts (8) further underlines the importance of investigating women's mental health status, especially in countries where life circumstances, in general, give rise to situations where multiple stressors might be at hand.

Detailed findings from studies indicate that the more severe and frequent the abuse, the more it impacts women's well-being $(9,10)$, and cumulative and concurrent exposure to physical, sexual, and psychological abuse seems to be most detrimental to women's overall mental health (11). Several studies have further found that the prevalence of partner violence against women is higher in societies where gender roles are unequal (12), in deprived neighbourhoods, and among low socio-economic status families, especially where husbands are unemployed (13-15). All these factors contribute to elevate individuals' psychological distress. A recent study also describes how neighbourhood disorder, such as fighting, drug use, community conflicts, prostitution, and gang-related activity may increase partner violence and, in this way, augment individuals' psychological ill health and lower the overall quality of life (16). 
Pakistan is a low-income Muslim country with approximately 176 million inhabitants. Only $36 \%$ of the women can read and write, and the employment rate for women is $22.2 \%$, as compared with an average of $77.8 \%$ for men, with higher rates in urban areas $(17,18)$. The Pakistani society is male dominated, and the majority of women have to accept arranged marriages; further married women have to accept a certain degree of partner violence to secure the marriage and avoid social stigma (10). In daily life, women have to accept financial and other limitations due to their dependence on their husbands (19). The few social or legal organizations that do support women are mainly active in upper the socio-economic neighbourhoods, and are thus, of little use to most women (20). There are few population-based studies on IPV and related health effects from Karachi, Pakistan, even though facility-based studies indicate a high prevalence. A prevalence of physical violence ranging between 16 and $76 \%$ and for sexual violence it was $12-16 \%$. For psychological violence the prevalence found was from $23 \%$ and upwards to extremely high levels $(>60 \%)(19,21-25)$.

This community-based study focused on low and middle-income women in urban Karachi. It aimed to investigate the mental health effects and women's coping behaviours - such as disclosure rates and health care-seeking patterns, associated with the husbands' use of physical, sexual, and psychological violence.

\section{METHODS}

\section{Study design and population}

This cross-sectional study was performed in Karachi, a district within the Sindh province, with about 16 million inhabitants (17). It is further divided into 18 towns. The study included 759 
married women, aged 25 to 60 years, living in two of the towns with approximately 720,000 inhabitants. The response rate was $93.7 \%$.

Due to the restrictive attitudes related to women's movements and decision-making in the Pakistani society $(22,26)$, it was necessary to link up with a health organisation that maintains a surveillance system for data collection, and whose health workers were somewhat known to the community. Government health facilities were contacted initially, but as they lacked resources, we were advised to contact the Health and Nutrition Development Society (HANDS) $(27,28)$. HANDS is a non-governmental organization working closely with the Government health services. HANDS provides basic health facilities and also primary education, income-generating opportunities, and institutions to empower communities in low and middle-income areas of Karachi (27). HANDS' facilities are equipped with trained people who shoulder full responsibility for local health services at the primary care level (maternal and child health, immunization, oral re-hydration therapy, control of diarrhoeal diseases, nutrition counselling, growth monitoring and treatment of minor illnesses), and field sites have been established to follow up on the activities. Community midwives (CMs) with 18 months of training are available at the facilities to provide general antenatal and postnatal care, to assist during deliveries, and to provide family planning services. We relied on these midwives to collect data for this study (27, 28). HANDS shoulders the responsibility for health facilities in two of the towns (Gadap and Bin Qasim), and has established 10 health field sites in these towns $(17,18)$. For this study, six of these sites were randomly chosen for data collection. The population belongs mainly to the lower and middle socio-economic strata, and includes different ethnic groups (29). The data gathered 
from these two towns can, therefore, be generalised mainly to the lower and middle socioeconomic groups of Karachi $(27,29)$.

\section{Data collection instrument}

We used the Multi-country Study on Women's Health and Life Experiences Questionnaire, which was developed by the World Health Organization (WHO) for studies within public health, with a focus on interpersonal violence (30). The questionnaire is considered to be crossculturally appropriate. Until now, it has been used in more than 15 countries. The abuse questions were developed on the basis of a variety of other abuse assessment scales (Index of Spouse Abuse and the Conflict Tactics Scales) with established reliability and construct validity $(31,32)$.

This instrument was translated into Urdu, the national language widely spoken in Pakistan. A few items were regarded as being unacceptable in this context, and were hence excluded, for example, women's alcohol consumption patterns, whether women acted as heads of households, and if the husband had multiple sex partners. The questionnaire went through face and content validity assessment by experts, including a psychologist, an epidemiologist, a sociologist, a community-based medical doctor, the field supervisor, a public-health specialist, and the data

collectors. The final questionnaire contained items addressing socio-demographic variables and psychosocial factors, different forms of violence and their frequency, health effects of the violence inflicted, coping strategies, and health-care-seeking behaviours. 


\section{Data collection procedure and sampling}

The data was collected by community midwives employed by HANDS, from March to August 2008. A multi-stage random sampling technique (Selection of field sites and then selection of study participants) was used for identification of households to be approached in the selected area. In each field site and through the surveillance system set up by the CMs, the required number of households was randomly selected (using computer-generated numbers from Epi Info) from a list of all households where a woman of the required age was available. If a selected woman refused to participate, another woman from a neighboring household was approached. However, $41(5.1 \%)$ women decided to discontinue the interview when half-way through and these were not replaced. In a household with more than one eligible woman, only one was selected, by asking the youngest and the oldest alternately. Information related to the husbands was obtained from the women and relates to the current husband.

\section{Training of the data collectors}

Six CMs received training for one week, conducted by the main author in this study and a psychologist, in collaboration with the members of the Women Lawyers' Association (PAWLA $)^{1}$. The training included topics such as the rationale for the study, known prevalence and causes of IPV, women's vulnerability, ethical considerations, and communication and interview skills. Two of the interviewers left during the training period, while the remaining four continued.

\footnotetext{
${ }^{1}$ Pakistan Women Lawyers Association is a non-governmental organization that supports women's legal rights.
} 
Each interview was conducted in the local language, Urdu. The study was presented as a Women's Health study to the members of the household, and not until the conversation was safe from being overheard were any sensitive questions asked. The interviews were conducted in the respondent homes when privacy could be ensured, otherwise at a nearby school or HANDS facility. To ensure quality of data, about $5 \%$ of the participants were re-interviewed, selected at random for comparison. Only minor differences were detected in the responses given.

\section{Sample size}

In order to detect an increase in risk of 1.6 times of physical/sexual/psychological violence, with $80 \%$ probability and an estimated prevalence of this exposure of $20-30 \%$ in the study sample, we calculated that we needed a sample size of about 660 individuals (25). We therefore decided to aim for 800 respondents: however 810 were approached and eventually 759 women were included in the study.

\section{Variables}

IPV is defined by WHO as any act of physical, sexual, or psychological abuse by a current or former partner, whether cohabiting or not (33).

\section{Forms of violence}

Life time exposure to violence exercised by the husband was assessed by items forming composite measures for physical, sexual, and psychological violence respectively. Physical 
abuse was defined as slapping, throwing things, pushing or shoving, hitting, kicking, dragging, beating or burning. Sexual abuse was defined by two items: physically forced intercourse by the husband and performing sexual acts against the woman's will. Psychological abuse was defined by four items: insults or making the woman feel bad about herself, belittlement or humiliation in front of others, scaring or intimidating her on purpose, and threatening to hurt her or someone she cared about. A detailed analysis of the prevalence and risk factors for the different forms of violence has been presented elsewhere (34).

\section{Socio-demographic variables}

Socio-demographic variables were analyzed as independent risk factors. Age was dichotomized into younger and older age groups (25-35 and 36-60 years). Educational attainment was grouped into no education, primary (up to 8 years), secondary schooling (9 to 10 years), intermediate and higher education (11 years and more), and for multivariate purposes dichotomized into no formal education as opposed to any length of schooling. Women's and husbands' employment status was dichotomized into being employed or not. Those who were in paid employment were further categorized as unskilled workers (e.g. construction worker, messenger, landlord, farmer, watchman, servant, shopkeeper), skilled workers (e.g. fisherman, gardener, carpenter, trader, driver, tailor), and low and medium-level professionals (e.g. soldier, police officer, teacher, health professionals, receptionist, secretary, Lady Health Visitor, school teacher). This variable was further dichotomized into skilled workers including the professionals as opposed to unskilled workers.

Number of children was grouped into three categories: $0,1-4$, and $\geq 5$ children. 
The socio-economic status (SES) variable was constructed from a list of household assets. Each respondent marked the assets available in the household and these assets were assigned different weightage according to how common these tended to be in households, and according to the price in the market (e.g. electricity, radio, and television as ' 1 ', telephone, and computer as ' 2 ', and refrigerator and air conditioner as ' 3 '). The weightage were decided by a team of researchers from the Aga Khan University, on the basis of community-based studies. The weightage were summed up and divided into quartiles. Families within the lowest $25^{\text {th }}$ percentile were rated to be in the low SES category, as opposed to the medium and high SES categories.

\section{Mental health effects variables}

The women were asked about their general health using a five-point scale (excellent, good, fair poor, or very poor). The scale was later dichotomized into two categories: 'good and excellent' and 'fair, poor, and very poor'. All women were also asked about six mental health symptoms experienced during the past 12 months; the response categories being 'yes' and 'no. The symptoms were: 'difficulties in performing usual activities'; 'memory or concentration problems'; 'difficulties in decision making'; 'loss of interest in previously enjoyed things'; 'feeling worthless'; and 'experiencing suicidal thoughts'.

\section{Statistical analysis}

The Statistical Package for the Social Sciences (SPSS) version 10.0 was used for all statistical calculations (35). Frequency and differences between groups and the total population were calculated by using the Chi square test, with p-values for two independent proportions. The internal consistency (Cronbach alpha) for physical, sexual, and psychological violence sub-scales were $0.87,0.79$, and0 .93 respectively. 
Odds ratios (OR) with 95\% CI were used in the bivariate and multivariate analyses to estimate associations between violence exposure and mental health effects. Statistically significant variables in the bivariate analyses were entered into the multivariate model one at a time for causal chain and confounding analyses. Final models are displayed, adjusted for age and educational attainment of both husband and wife, and further for SES and husband's occupation.

\section{Ethical considerations}

The ethical principles for violence research spelt out by the World Health Organization (WHO) were strictly followed (11). All respondents were informed about their free choice to participate and to withdraw whenever they wished during the research phase. Data collectors secured written consent from all respondents preceding the interview. Those women who disclosed experiences of violence and expressed a need for support were referred to the PAWLA and the Women's Social Security Department, Government of Pakistan, for consultations with mental health professionals and lawyers, free of charge. Women from the community were also provided with awareness sessions on women's rights by lawyers. The study was approved by the Institutional Ethical Review Committee of the Aga Khan University in Karachi, Pakistan. Linking up with the HANDS organization facilitated the data collection process greatly, as the data collectors were somewhat known in the area. Unfamiliar women introducing themselves as data collectors would hardly have been accepted by the families. Furthermore, data collectors unfamiliar to the households might have been put at personal risk. 


\section{RESULTS}

Of the 759 women, the majority (59\%) was between 25 and 35 years old (Table 1). Fewer women than men had attended school (52.4\% and $63.8 \%$, respectively). Most of the women were housewives and practiced Islam. Almost all of the husbands (98\%) were employed and most of them $(66 \%)$ were unskilled workers. Only $14.5 \%$ of the women were in paid employment. The prevalence of life-time physical, sexual, and psychological violence was 57.6, 54.5, and $83.6 \%$, respectively (36). In the entire study population, the adverse mental health condition most commonly reported was suicidal thoughts $(58.8 \%)$, followed by feelings of worthlessness (42.3\%) and difficulties in decision-making (35.3\%) (Table 2). 'Fair, poor or very poor general health' was reported by $48.7 \%$.

\section{Violence exposure and symptom reporting}

The prevalence of poor mental health was considerably higher among women exposed to any form of violence as compared to women not exposed to violence, with statistically significant differences for most of the health conditions included.

Suicidal thoughts were reported by as many as $74.1 \%, 75.8 \%$, and $65.3 \%$ of the women subjected to physical, sexual, and psychological violence, respectively. The category of 'Feelings of worthlessness' was also highly prevalent, reported by $47.8 \%$ of those subjected to physical violence, by $51.7 \%$ of those subjected to sexual violence, and by $49.2 \%$ of those reporting exposure to psychological violence.

(Table 2). 
In the multivariate analysis, after adjusting for socio-demographic variables, all of the health variables displayed statistically significant associations with physical violence. In the case of sexual violence, only 'memory and concentration problems' did not display statistically significant odds ratios (OR), and 'loss of interest in previously enjoyed things' did not emerge as a statistically significant factor for psychological violence (Table 3).

A striking finding was the strong association found between the three forms of violence and suicidal thoughts. In the case of physical and sexual violence, the risk of suicidal thoughts was elevated four times (adjusted odds ratio, aOR, for physical violence 4.41; 3.18-6.12, for sexual violence aOR $4.39 ; 3.17-6.07)$ compared to those not exposed to any of the forms of violence. In the case of psychological violence, the aOR was 5.17 (3.28-8.01).

As suicidal thoughts were extremely prevalent in the total study population, and strongly associated with all forms of violence, an attempt was made to investigate some underlying reasons. Women subjected to any of the forms of violence, reported 'family problems' (45\%) as the most important reason for suicidal thoughts, followed by 'household work' (9 \%) and 'husband's behaviour (6 \%). A few reported reasons such as son's death, quarrel in the family, fed up with life, childlessness, illness, and depression. The pattern was the same for the total population.

\section{Coping strategies and healthcare seeking}

An important coping mechanism is to confide in someone, if it can be done without fear of repercussion. Only $177(27.4 \%)$ out of the 646 women who were subjected to any form of 
violence confided in someone, mainly parents $(n=132 ; 20.4 \%)$, followed by friends $(n=34 ; 5.3$ $\%)$, and in-laws $(\mathrm{n}=7 ; 1.1 \%)$. Only $24.9 \%(\mathrm{n}=161)$ had sought help and protection actively, and this was mainly from the parents $(n=128 ; 19.8 \%)$ but also from the in-laws $(n=29 ; 4.5 \%)$, brothers and sisters $(n=10 ; 1.5 \%)$, friends $(n=10 ; 1.5 \%)$, and children $(n=7 ; 1.1 \%)$. Only a few had sought assistance from any official body, such as the healthcare services, any judicial authority, or a religious leader $(n=10,1.5 \%)$. Of these, just one woman had turned to the health care services, two had contacted the social services, one had sought legal advice, and six had turned to religious leaders.

\section{DISCUSSION}

Our findings provide new information as they suggest a high prevalence of a variety of mental health symptoms, not least suicidal thoughts, among Pakistani women, and demonstrate strong associations with all forms of violence exposure. There was a more than 4-fold risk increase of suicidal thoughts for women exposed to any of the forms of violence investigated. Very few of the exposed women sought assistance from any legal authority or from the health care services, some, however, confided in relatives. This provides indications of Pakistani women's seriously impaired mental health status, with society offering few options for help and support.

Suicidal thoughts must be regarded as a serious matter, potentially leading to suicide attempts, some of which might result in actual suicide. A strong association between all forms of violence and suicidal thoughts is also commonly found in other studies, where the same questionnaire was used (3-5). The reasons stated for reporting suicidal thoughts in this study were mainly family problems, household work, and husband behaviour. These are rather general statements and 
unfortunately, factors underlying the family problems were not penetrated further. A review article from Pakistan, in which a number of studies were analysed, found that the prevalence of anxiety and depression ranged between 25 and $66 \%$ among married women (37), but there is no available population-based data on the number of suicide cases. According to a press report, of 4069 cases of violence against women reported to the police authorities, $7 \%(n=285)$ did commit suicide (38). These registered cases are most probably have been severe in nature, because otherwise they would never have been reported to any authority.

'Problems in performing usual activities', 'difficulties in decision-making', 'loss of interest in previously enjoyed things', 'feelings of worthlessness' 'memory and concentration problems' and 'suicidal thoughts' are six symptoms that signal depression, as defined in the Diagnostic and Statistical Manual of Mental Disorders (DSM IV) (39). As these symptoms were commonly reported by the women subjected to violence in this study, it seems plausible they would have been diagnosed with clinical depression had they sought health care. The women exposed to physical violence reported 'extreme memory or concentration problems', which might be an indication of depression, post-traumatic stress disorder, or even minor brain injury (40).

'Feelings of worthlessness' and 'suicidal thoughts', might also signal lowered self-esteem. It has been shown in studies from Palestine and Ethiopia that the longer a woman stays in an abusive relationship, the greater the risk of lowered self-esteem $(41,42)$. A corresponding finding was reported from a pooled analysis of studies, using the same questionnaire in 10 countries (3). In studies from Sweden, a similar phenomenon is referred to as the 'normalisation process', in which the abused woman gradually comes to consider the violence as 'normal' and herself as the 
blameworthy party with serious loss of self-esteem (43). Considering the impaired ability to leave the relationship, due to the stigma associated with separation and divorce or this elevates the risk of suicide (43).

Moreover, applying the ecological framework, as initially described by Bronfenbrenner, can help further to understand the high levels of mental ill health found among women in this study. The ecological model explains how individuals' development, health and well-being are influenced by multiple factors in larger social systems, such as the family, neighbourhoods, communities and finally the macro system forming laws and regulations (15). Especially important at the macro level is the 'culture' in each society as the carrier of ideology, roles, activities and their interrelations (15); at this level are also gender roles constructed. Pakistani women from low and middle income families live with multiple stressors related to different levels in the ecological model, such as forced marriages, dowry, and restricted mobility, which affects their education and work opportunities. Women are often excluded from domestic decision-making and are confined to do housework for the extended family; whereby the prospects of women's empowerment decrease. Our data show that $70 \%$ of the women had not chosen their husband; however, almost all denied dowry being involved in the marriage, but $93 \%$ admitted that bride price had been paid to them directly. High educated women face better life prospects (44). This mobility is restricted due to civil unrest currently, present in the country, with compromised personal and family safety, which also possibly limits families from engaging in activities that they enjoyed outside of the home, adds to the already existing psychological stress in women. 
Women are in an inferior position as compared to men in the Pakistani society; women's overall life circumstances are characterised by serious gender inequalities with limited possibilities to leave the marriage (44). Men's violence against women within marriage is further accepted as a part of the cultural norm, particularly by older and poorly educated women $(17,20)$. The power imbalance between husband and wife may well explain symptoms of depression and also the high occurrence of suicidal thoughts in married women, whether or not exposed to any form of violence.

Just about a quarter of the women disclosed their husband's abusive behaviours to anyone. Those who did so most often turned to their parents rather than seeking help from legal institutions. This is not a surprising finding, as there are few legal authorities by which a woman will be taken seriously when reporting violence and abuse from her husband (45). Of the injured women, more than half had to seek healthcare, indicating that they were seriously injured.

\section{Methodological considerations}

This study used the WHO questionnaire for data collection, which makes the results comparable to findings from other countries where the same instrument was used. This is the first study to collect data at the household level in Pakistan, and it comprises a comparatively large sample from a country where there are extreme difficulties related to investigating such a delicate subject. The response rate in this study - 93.7\% - is quite high, possibly due to the data being collected by community midwives (CM) who were established in the communities and are trusted by the local people. The health conditions inquired about were all rather well-specified mental symptoms, apart from 'general health'. Asking about symptoms expressed as feelings, 
such as 'feeling worthless' or 'losing interest in things you used to enjoy' are clearer and create less confusion than asking about 'depression', thereby rendering a more accurate response.

This was a cross-sectional study and no conclusions can be drawn with respect to the direction of the associations. However, the data was used for life-time prevalence of different forms of violence exerted by the husband, whereas the symptoms were reported as having occurred in the past year. Due to this temporal relationship, it seems plausible that the exposure to violence and abuse gave rise to a higher level of mental health symptoms and not the reverse.

The participants were randomly chosen from within two of the towns of the city of Karachi, comprising of low and middle-income populations. We were not able to approach the highest income strata as they mainly use private health facilities and no community midwives are placed in such areas. Therefore, our findings are representative mainly of the low and middle-income groups of the general population in urban Karachi.

It is theoretically possible that women who report serious ill-health, such as symptoms of depression and suicidal tendencies, are more prone to report events of violence. However, we found statistically significant differences in the prevalence of almost all the health variables between those who reported violent events and those who did not, which makes this possibility unlikely. 


\section{CONCLUSION}

The findings in this study point at IPV and other stressors women face that cumulatively contribute to the development of different forms of psychological stress and serious mental ill health. Further studies are needed to confirm our findings, qualitative and quantitative, to gain detailed knowledge and understanding of women's overall life circumstances and mental health outcomes. Few of the exposed women sought any health care, social care, or legal support, which implies lack of such bodies that are reliable for women to turn to.

The present situation requires urgent attention at all levels of social organisation - by policymakers, political stakeholders at macro the level and professionals at micro level, to improve and safeguard women's overall life circumstances. Women should be offered the possibility to report violent incidents without fear of repercussion and they should be provided with high-quality health care and social support and security when in need. A reliable health surveillance system should be established to follow up on these matters to ensure that early identifications of victims and management of the IPV take place. In addition, health care professionals should become better educated about the problem of violence within relationships, be able to identify mental symptoms, and should be encouraged to act when suspecting such cases, by referring to legal aid, counselors, and non-governmental organizations. However, many doctors/nurses do not ask women about violence experience and are poorly prepared to respond to the needs of the victims. Therefore, there is a need to ensure knowledge about Violence against women is provided clearly in the medical and nursing academic education. 
Parallel to all these necessary steps there is an urgent need to improve gender equality.

Programmes designed to change norms and beliefs should be put in place encouraging people to discuss, and untraditional communication channels could be tried, such as role plays, theatre.

The mass media should generate a public debate on the serious IPV, and gender inequalities that exist in the country and condemn such violations.

\section{Authors' contributions}

The first and the last author are responsible for the conception and design, acquisition of data, analysis and interpretation of data, drafting the article or revising it critically for important intellectual content and final approval for the version to be published. The second author's contribution is the interpretation of data, revising it critically for important intellectual content, and final approval of the version to be published.

\section{Acknowledgements}

This study was made possible by a grant from STINT (The Swedish Foundation for International Cooperation in Research and Higher education) and by support from the Swedish Institute. This study has also been supported by the School of Nursing and The Community Health Department at The Aga Khan University, Karachi, Pakistan. The Department of Social Medicine at Gothenburg University and Department of Public Health Sciences, Division of Global Health (IHCAR), Karolinska Institute, Stockholm, Sweden provided support during manuscript analysis and preparation. 
We want to thank HANDS, a non-governmental organisation that supported and facilitated the data collection and allowed the use of their surveillances system. We also want to acknowledge PAWLA (Pakistan Women Lawyers' Association) and Women's social welfare department for their strong support in the training of the data collectors. Last, but not least, we want to thank the women who participated, for their trust and confidence in this study.

\section{Copyright}

The corresponding author has the right to grant, on behalf of all authors, this exclusive copyright licence. We, the authors, give the copyright to print this article, to the International Journal of Behavioural Medicine after it has been accepted by IJBM.

\section{Disclosure of interest}

The authors clarify that there is no financial relationship with the organization that sponsored the research. The authors have full control of all the primary data and, if needed we can allow the journal to review our data. Upon acceptance of our manuscripts, the authors will complete the form of 'Disclosure of Interest' for the editorial office. 


\section{References}

1. Garcia-Moreno C, Heise L, Jansen H. Public health. Violence against women. Science. 2005;310(5752):1282 - 3 .

2. Carbone-Lopez K, Kruttschnitt C, Macmillan R. Patterns of intimate partner violence and their associations with physical health, psychological distress, and substance use. Public Health Reports. 2006 Jul-Aug;121(4):382-92.

3. Ellsberg M, Jansen H, Heise L, Watts CH, Garcia-Moreno C, Hlth WHOMSW. Intimate partner violence and women's physical and mental health in the WHO multi-country study on women's health and domestic violence: an observational study. Lancet. 2008;371(9619):1165-72. 4. Vung ND, Ostergren PO, Krantz G. Intimate partner violence against women, health effects and health care seeking in rural Vietnam. European Journal of Public Health. 2009 Apr;19(2):178-82.

5. Bonomi AE, Anderson ML, Rivara FP, Thompson RS. Health outcomes in women with physical and sexual intimate partner violence exposure. Journal of Womens Health. 2007;16(7):987-97.

6. Ludermir AB, Schraiber LB, D'Oliveira A, Franca-Junior I, Jansen HA. Violence against women by their intimate partner and common mental disorders. Social Science \& Medicine. 2008 Feb;66(4):1008-18.

7. Deyessa N, Berhane Y, Alem A, Hogberg U, Kullgren G. Depression among women in rural Ethiopia as related to socioeconomic factors: A community-based study on women in reproductive age groups. Scandinavian Journal of Public Health. 2008 Aug;36(6):589-97.

8. Devries K, Watts C, Yoshihama M, Kiss L, Schraiber LB, Deyessa N, et al. Violence against women is strongly associated with suicide attempts: Evidence from the WHO multicountry study on women's health and domestic violence against women. Social Science \& Medicine.73(1):79-86.

9. Campbell JC, Kub J, Belknap RA, Templin TN. Predictors of depression in battered women. Violence Against Women. 1997;3(3):271.

10. Pico-Alfonso MA, Garcia-Linares MI, Celda-Navarro N, Blasco-Ros C, Echeburúa E, Martinez M. The impact of physical, psychological, and sexual intimate male partner violence on women's mental health: depressive symptoms, posttraumatic stress disorder, state anxiety, and suicide. Journal of Women's Health. 2006;15(5):599-611.

11. Houry D, Kemball R, Rhodes KV, Kaslow NJ. Intimate partner violence and mental health symptoms in African American female ED patients. The American journal of emergency medicine. 2006;24(4):444-50.

12. Antai D. Controlling behavior, power relations within intimate relationships and intimate partner physical and sexual violence against women in Nigeria. Bmc Public Health.11(1):511.

13. Benson ML, Fox GL, DeMaris A, Van Wyk J. Neighborhood Disadvantage, Individual Economic Distress and Violence Against Women in Intimate Relationships. Journal of Quantitative Criminology. 2003;19(3):207-35.

14. Cunradi CB, Caetano R, Clark C, Schafer J. Neighborhood Poverty as a Predictor of Intimate Partner Violence Among White, Black, and Hispanic Couples in the United States: A Multilevel Analysis. Annals of epidemiology. 2000;10(5):297-308.

15. Bronfenbrenner U. Toward an experimental ecology of human development. American psychologist. 1977;32(7):513. 
16. Beeble M, Sullivan C, Bybee D. The Impact of Neighborhood Factors on the Well-Being of Survivors of Intimate Partner Violence Over Time. American Journal of Community Psychology.47(3):287-306.

17. Calverton M. Pakistan Demographic Health Survey 2006-7. Macro International Inc, 2007. Pakistan: Government of Pakistan; 2007.

18. Sadaquat MB. Employment situation of women in Pakistan. International Journal of Social Economics.38(2):98-113.

19. Rabbani F QF, Rizvi N. Perspectives on domestic violence: case study from Karachi, Pakistan. East Mediterr Health J. [Original article]. 2008;14(2):415-26.

20. Hyder AA, Merritt M, Ali J, Tran NT, Subramaniam K, Akhtar T. Integrating ethics, health policy and health systems in low- and middle-income countries: case studies from Malaysia and Pakistan. Bulletin of the World Health Organization. 2008 Aug;86(8):606-11.

21. Fikree FF, Bhatti LI. Domestic violence and health of Pakistani women. Int J Gynaecol Obstet. 1999 May;65(2):195-201.

22. Karmaliani R, Irfan F, Bann C, McClure E, Moss N, Pasha O, et al. Domestic violence prior to and during pregnancy among Pakistani women. Acta Obstetricia Et Gynecologica Scandinavica. 2008;87(11):1194-201.

23. Khan A, Hussain R. Violence against Women in Pakistan: Perceptions and Experiences of Domestic Violence. Asian Studies Review. 2008;32(2):239 - 53.

24. Shaikh MA. Domestic violence against women--perspective from Pakistan. J Pak Med Assoc. 2000 Sep;50(9):312-4.

25. Fikree FF, Jafarey SN, Korejo R, Khan A, Durocher JM. Pakistani obstetricians' recognition of and attitude towards domestic violence screening. International Journal of Gynecology \& Obstetrics. 2004 Oct;87(1):59-65.

26. Andersson N, Cockcroft A, Ansari N, Omer K, Chaudhry UU, Khan A, et al. Collecting reliable information about violence against women safely in household interviews: experience from a large-scale national survey in South Asia. . Violence Against Women. 2009;15(4):482-96. 27. Health And Nutrition Development Society. Karachi2010 [cited 2010 June 5, 2010]; About HANDS]. Available from: http://www.hands.org.pk/abouthands/abouthands.htm.

28. City District Government Karachi: Kolachi to Karachi. [cited 2010 1/07/10]; Available from: http://www.karachicity.gov.pk/.

29. Rozi S, Akhtar S, Ali S, J. K. Prevalence and factors associated with current smoking among high school adolescents in Karachi, Pakistan. Southeast Asian J Trop Med Public Health. 2005;36(2):498-504.

30. WHO Multicountry study on women's health and life experiences questionnaire (version 9). Geneva: World Health Organisation; 2000.

31. Hudson WW, McIntosh SR. THE ASSESSMENT OF SPOUSE ABUSE - 2 QUANTIFIABLE DIMENSIONS. Journal of Marriage and the Family. 1981;43(4):873-\&.

32. Straus MA, Hamby SL. The revised conflict tactics scales. Development and preliminary psychometric data. The revised conflict tactics scales. Development and preliminary psychometric data. . Journal of Family Issues. 1996.;17:283-316.

33. Krug EG, Mercy JA, Dahlberg LL, Zwi AB. The world report on violence and health Lancet. 2002;360(9339):1083-8.

34. Ali TS, Asad N, Mogren I, Krantz G. Intimate Partner Violence in urban Pakistan: Prevalence, Frequency and Risk factors Submitted to International Journal of Women Health. December, 2010. 
35. Kinnear P GC. SPSS for Windows made simple. Release 10 Aberdeen. University of Aberdeen;; 2001.

36. Ali TS, Asad N, Mogren I, Krantz G. Intimate Partner Violence in urban Pakistan:

Prevalence, Frequency and Risk factors Accepted to International Journal of Women's Health January, 2011.

37. Mirza I, Jenkins R. Risk factors, prevalence, and treatment of anxiety and depressive disorders in Pakistan: systematic review. British Medical Journal. 2004 Apr;328(7443):794-7.

38. Incidents of Violence against Women in Pakistan: Reported during January to June 2010

In: Pakistan Go, editor. Islamabad2010.

39. Association AP. Diagnostic and statistical manual of Mental disorders 4ed: Washington, DC: American Psychiatric Press; 1994.

40. Campbell JC. Health consequences of intimate partner violence. Lancet. 2002 Apr 13;359(9314):1331-6.

41. Haj-Yahia M. The impact of wife abuse on marital relations as revealed by the Second Palestinian National Survey on Violence Against Women. J Fam Psychol. 2002;16(3):273 - 85.

42. Deyessa N, Berhane Y, Alem A, Ellsberg M, Emmelin M, Hogberg U, et al. Intimate partner violence and depression among women in rural Ethiopia: a cross-sectional study. Clinical Practice and Epidemiology in Mental Health. 2009;5(1):8.

43. Lundgren E, Heimer G, Westerstrand J, Kalliokoski A. Slagen dam. Mäns våld mot kvinnor i jämställda Sverige-en omfångsundersökning [Captured queen- men's violence against women in equal Sweden - a prevalence study]. Ume\&aring, Sweden: Fritzes Offentliga Publikationer. 2001.

44. Niaz U. Women's mental health in Pakistan. World Psychiatry. 2004;3(1):60.

45. Andersson N, Cockcroft A, Ansari U, Omer K, Ansari NM, Khan A. Barriers to Disclosing and Reporting Violence Among Women in Pakistan: Findings From a National Household Survey and Focus Group Discussions. Journal of interpersonal violence.25(11):1965. 
Table 1: Socio-demographic and psychosocial factors of respondents and their husbands.

$\mathbf{N}=759$

\begin{tabular}{|c|c|c|}
\hline Characteristics & $n=759$ & $\%$ \\
\hline \multicolumn{3}{|l|}{ Respondents } \\
\hline \multicolumn{3}{|l|}{ 1. Age groups (years) } \\
\hline $25-35$ & 447 & 58.9 \\
\hline $36-45$ & 228 & 30.0 \\
\hline $46-60$ & 84 & 11.1 \\
\hline \multicolumn{3}{|l|}{ 2. Education } \\
\hline No formal education & 361 & 47.6 \\
\hline Primary School $(<6$ years $)$ & 175 & 23.1 \\
\hline Secondary school $(6-10$ years $)$ & 197 & 26 \\
\hline Intermediate and university education ( $>11$ years) & 26 & 3.4 \\
\hline \multicolumn{3}{|l|}{ 3. Employed } \\
\hline Yes & 110 & 14.5 \\
\hline No & 649 & 85.5 \\
\hline \multicolumn{3}{|l|}{ 4. Occupation } \\
\hline Housewives & 649 & 85.5 \\
\hline Unskilled workers & 18 & 2.4 \\
\hline Skilled workers & 51 & 6.7 \\
\hline Low and medium level professionals & 42 & 5.5 \\
\hline \multicolumn{3}{|l|}{ Husbands/Partners } \\
\hline \multicolumn{3}{|l|}{ 5. Age groups (years) } \\
\hline $25-35$ & 307 & 40.4 \\
\hline $36-45$ & 263 & 34.7 \\
\hline $46-90$ & 189 & 24.9 \\
\hline \multicolumn{3}{|l|}{ 6. Education } \\
\hline No formal education & 275 & 36.2 \\
\hline Primary School (< 6 years) & 89 & 11.7 \\
\hline Lower secondary school $(6-10$ years $)$ & 126 & 38.6 \\
\hline Intermediate and university education (>11 years) & 102 & 13.4 \\
\hline \multicolumn{3}{|l|}{ 7. Employed } \\
\hline Yes & 746 & 98.3 \\
\hline No & 13 & 1.7 \\
\hline \multicolumn{3}{|l|}{ 8. Occupation } \\
\hline Unskilled workers & 500 & 65.9 \\
\hline Skilled workers & 145 & 19.1 \\
\hline Low and medium level professionals & 101 & 13.3 \\
\hline \multicolumn{3}{|l|}{ Family factors } \\
\hline 9. Socio economic status ( SES) & & \\
\hline
\end{tabular}


Mental health effects of IPV

\begin{tabular}{|l|l|l|}
\hline Low socio economic (SES) status & 242 & 31.9 \\
\hline Medium SES & 192 & 49.3 \\
\hline High SES & 143 & 18.8 \\
\hline $\mathbf{1 0}$ Number of children & & \\
\hline 0 children & 41 & 5.4 \\
\hline $1-4$ children & 470 & 61.9 \\
\hline $5-$ or more & 248 & 32.7 \\
\hline 11. Number of family members & & \\
\hline $1-4$ family members & 266 & 35.0 \\
\hline $5-17$ family members & 493 & 65.0 \\
\hline
\end{tabular}


Table 2 Prevalence of different health conditions in the total population of women, and in women with lifetime experience of physical, sexual or psychological violence. $N=759$

\begin{tabular}{|c|c|c|c|c|c|c|c|}
\hline Health condition & $\begin{array}{l}\text { Total } \\
\text { populatio } \\
\text { n(\%) }\end{array}$ & $\begin{array}{l}\text { Physical } \\
\text { violence } \\
\mathbf{n}=437 \\
(\%)\end{array}$ & p-value* & $\begin{array}{l}\text { Sexual } \\
\text { violence } \\
\mathrm{n}=414(\%)\end{array}$ & p-value* & $\begin{array}{l}\text { Psycholog } \\
\text { ical } \\
\text { violence } \\
\mathrm{n}=634 \\
(\%)\end{array}$ & p-value* \\
\hline \multicolumn{8}{|l|}{ General health } \\
\hline Good or excellent & $389(51.3)$ & $197(45.1)$ & & $191(46.1)$ & & $290(45.7)$ & \\
\hline Fair, poor, or very poor & $370(48.7)$ & $240(54.9)$ & $<0.001$ & $223(53.9)$ & 0.001 & $344(54.3)$ & $<0.001$ \\
\hline \multicolumn{8}{|l|}{ Performing usual activities } \\
\hline No problems or very few problems & $678(89.3)$ & $368(84.2)$ & & $355(85.7)$ & & $557(87.9)$ & \\
\hline Many problems & $81(10.7)$ & $69(15.8)$ & $<0.001$ & $59(14.3)$ & $<0.001$ & $77(12.1)$ & 0.001 \\
\hline \multicolumn{8}{|l|}{$\begin{array}{lll}\begin{array}{l}\text { Memory } \\
\text { problems }\end{array} & \text { or } & \text { concentration }\end{array}$} \\
\hline No, few, or some problems & $522(68.8)$ & $260(59.5)$ & & $269(65.0)$ & & $411(64.8)$ & \\
\hline Extreme problems & $237(31.2)$ & $177(40.5)$ & $<0.001$ & $145(35.0)$ & 0.008 & $223(35.2)$ & $<0.001$ \\
\hline \multicolumn{8}{|l|}{ Difficulties in decision making } \\
\hline No & $491(64.7)$ & $262(60.0)$ & & $211(51.0)$ & & $402(63.4)$ & \\
\hline Yes & $268(35.3)$ & $175(40.0)$ & 0.001 & $203(49.0)$ & $<0.001$ & $232(36.6)$ & 0.058 \\
\hline \multicolumn{8}{|l|}{$\begin{array}{l}\text { Loss of interest in previously } \\
\text { enjoyed things }\end{array}$} \\
\hline No & $537(70.8)$ & $287(65.7)$ & & $257(62.1)$ & & $443(69.9)$ & \\
\hline Yes & $222(29.2)$ & $150(34.3)$ & $<0.001$ & $157(37.9)$ & $<0.001$ & $191(30.1)$ & 0.138 \\
\hline \multicolumn{8}{|l|}{ Feelings of worthlessness } \\
\hline No & $438(57.7)$ & $228(52.2)$ & & $200(48.3)$ & & $322(50.8)$ & \\
\hline Yes & $321(42.3)$ & $209(47.8)$ & $<0.001$ & $214(51.7)$ & $<0.001$ & $312(49.2)$ & $<0.001$ \\
\hline \multicolumn{8}{|l|}{ Suicidal thoughts } \\
\hline No & $313(41.2)$ & $113(25.9)$ & & $100(24.2)$ & & $220(34.7)$ & \\
\hline Yes & $446(58.8)$ & $324(74.1)$ & $<0.001$ & $314(75.8)$ & $<0.001$ & $414(65.3)$ & $<0.001$ \\
\hline
\end{tabular}

$* \mathrm{p}$ values for difference between exposed and non-exposed for each specific type of violence 
Table 3. Associations between selected health conditions in women with life-time experience of physical, sexual or psychological violence, adjusted odds ratios with their $95 \%$ confidence intervals. $N=759$.

\begin{tabular}{|l|l|l|l|}
\hline Health conditions & $\begin{array}{l}\text { Physical violence } * \\
(\mathbf{n = 4 2 7})\end{array}$ & $\begin{array}{l}\text { Sexual violence * } \\
(\mathbf{n = 4 0 2})\end{array}$ & $\begin{array}{l}\text { Psychological } \\
\text { violence * }(\mathbf{n = 6 2 1})\end{array}$ \\
\hline Fair/ poor/very poor general health & $1.50(1.10-2.05)$ & $1.27(0.93-1.74)$ & $3.68(2.302-6.00)$ \\
\hline $\begin{array}{l}\text { Many problems in performing usual } \\
\text { activities }\end{array}$ & $4.10(2.09-7.91)$ & $2.22(1.28-3.85)$ & $3.70(1.26-10.54)$ \\
\hline $\begin{array}{l}\text { Extreme memory or concentration } \\
\text { problems }\end{array}$ & $2.40(1.70-3.40)$ & $1.33(0.95-1.86)$ & $3.43(1.90-6.30)$ \\
\hline $\begin{array}{l}\text { Difficulties in decision-making } \\
\text { Loss of interest in previously enjoyed } \\
\text { things }\end{array}$ & $1.56(1.10-2.30)$ & $2.01(1.40-2.90)$ & $1.12(0.68-1.81)$ \\
\hline $\begin{array}{l}\text { Feelings of worthlessness } \\
\text { Suicidal thoughts }\end{array}$ & $1.70(1.22-2.30)$ & $2.23(1.63-3.10)$ & $1.59(1.10-2.51)$ \\
\hline
\end{tabular}

*Adjusted for woman's age, husband's age, woman's education, husband's education, socioeconomic status and husband's occupation. 